\title{
DIGITAL DIVIDE AND FUNDAMENTAL RIGHTS
}

Guido Saraceni ${ }^{1}$

\section{Abstract}

Because of the large spread of ICTs the world has become a truly global one. ICTs have landed a thousand walls, allowing people to get in touch regardless of distances and natural boundaries that once upon a time were considered insurmountable. Thus, digital divides is (are) still a big problem. A similar gap does not only concern the shameful inequality that separates rich and poor. From a cultural point of view, it indicates the uneven diffusion of the skills needed to obtain a benefit from the use of digital tools. As a matter of fact, digital divide(s) can be thought as the most important problem that we have to face, if we want to guarantee a complete and fair fruition of fundamental rights.

Keywords

Digital divide(s). Fundamental rights. World wide web. ICT. Discrimination.

\section{Summary}

1. Introduction 2. A so called "web" 3. The Digital Divide(s) 3.1 In Europe... 3.2... and in Italy 4. The Ancient Duty of Feeding the Hungry in the Roots of the European Culture 5. Conclusions. 6. References.

${ }^{1}$ Associate Professor. Department of Law. University of Teramo - Italy. 


\section{INTRODUCTION}

The term "digital divide" refers to the many and dangerous inequalities which characterize contemporary society regarding the access to - and the use of - ICT. The first border is the possession of a computer and the access to the World Wide Web. Besides this first border, which separates, as it's obvious, rich and poor, there are many others, which do not depend on a mere lack of means, but, more exactly, on cultural deficits. These digital divides are perhaps less evident, but equally or even more dangerous than the economic one. They cross each and every society in a transversal way, separating males and females, young and old, workers and unemployed, "sane" and disabled people. By this way, the digital divide adds to other and more ancient forms of discrimination, increasing, if possible, their damaging charge.

The spread of ICT has made the world a truly global one. As ICT have landed a thousand walls, allowing people to get in touch regardless of distances and natural boundaries that once upon a time were considered insurmountable. Thus, digital divide represents the last and most important wall we have to break down, if we want to create a free, democratic, completely and peacefully interconnected world. Furthermore, digital divides affects the enjoyment of fundamental rights: not being able to use the digital means of communication means not being able to enjoy the right to be informed, the right to work, the right to participate actively to the political life of one's Country or the right to health - just to mention the very first suggestions that immediately come to mind. In this paper, I will start from the birth and growth of the Internet, then, I will describe my view of the digital divide as specific kind of poverty, finally, I will discuss how the lack of digital means and competence can affect the enjoyment of fundamental rights. 


\section{A SO CALLED "WEB"}

Many legends are told about the birth of the Internet... the truth is that nobody, until today, has been able to tell us exactly how and why it was created. Maybe, we'll never know. The oldest origins of the net are totally shrouded in mystery. It could not be otherwise, seen that the first network, called Arpanet, was born in a military environment and covered by the most rigid secret. It was not a self-contained experiment, it was not itself a national defense project, but an experiment that started in such a casual and residual way. When the Russians, in 1969, launched the Sputink, Americans feared they had been seriously left behind in the race to space. Therefore, they decided to invest large sums of money in a top-secret project which should have been developed by the Department of Defense - called ARPA.

ARPANET, was indeed the first intranet, an "internal" network of the defense department. It was used to facilitate the work of researchers, by putting their computers into communication. This first network had neither the characteristics nor the ambition to become a global one. Most likely, even the researchers who worked on the very first prototype could never imagine the incredible consequences and the epochal developments that came later thanks to the work of the researchers at CERN - in Geneva where a center of excellence subsidized with public money invented the hypertext and the resource locator - the so called: "http" and "url". Without the creation of these phenomenal tools, the world wide web would never have reached the size and weight that it currently holds. It would have remained a tool reserved to a small group of experts: something difficult to use and not attractive for ordinary people. If Internet stopped at its very first state, nowadays the digital divide would be such a specific topic, something interesting for the academics, but completely irrelevant for the masses. CERN researchers themselves admitted that they have succeeded 
in their efforts by exploiting the anonymous and free work of the global hacker community ${ }^{2}$.

Initially, the web was conceived as a set of meaningful islands - called sites - connected by one or more links. The first version of the internet was not different from a huge library, where users could go to consult books, essays and articles written by authors. Yet this first version represented a cultural innovation with truly epochal proportions. Because, unlike libraries, the Internet is free; it can contain an infinite number of books and documents; it houses documents written in hypertext, and then connected by a dense network of semantics; it contains multimedia documents, enriched with images, sounds and movies.

Moreover, Internet made possible a total and flexible indexing of its contents - while a library allows a rigid and partial indexing: it allowed its user to react to the information. As a matter of fact, in that very first phase, the network consisted of sites designed and built by people who had at least a minimal computer competence and from forums, messages, chats dedicated to the common users. The next revolution came within ten years, when we moved from the first version to the so-called web $2.0^{3}$.

This second "version" of the network is characterized by the spread and success obtained by social networks. Following a conceptual paradigm that was inaugurated by the developers of google - the most important search engine in the world - the internet has made a decisive step forward towards its users. To date, the main value of the network certainly does not lie in sites, information and documents specially created by the State, Private

2 CASTELLS 2002, 21-44; 2008; BARABÀSI 2004, 155-172; RHEINGOLD 2003; BERNERS LEE 2001, 2007.

${ }^{3}$ LEVY 1999; LESSIG 2006; JOHNSON 2004; AMATO MANGIAMELI 2005; G. SARACENI 2008, 105-135. 
Companies or professionals, but it essentially consists in the content spontaneously produced and freely distributed by users themselves.

We then moved from a first phase, in which the user was a person who entered the network essentially to search for information and only secondarily to express his ideas; to a phase in which the user access the network in the first place to express himself, share his ideas and discuss with other users and only secondarily to look for information. These brave new mean of communication for the masses have definitively overturned the relationship between producers and consumers of information. With many and not yet completely clear consequences for politics and State sovereignty.

Probably, the most interesting thing is that this revolution radically changed the social value of the web. Therefore, it changed the role and the sense of the digital divide. Being excluded from the Internet, today, does not simply mean not having access to the larger and free library in the world. Of course, this would be bad enough. There is something much more important at stake. Being excluded from the network means not being able to take part in the public debate. Because of the growth of the social network, the whole web has been converted into a big global plaza where citizens, politicians, local and international actors meet - and often clash - to declare their existence or publish their political claims - the last sensational case is represented by the international movement called "me too".

In other words: being cut off from the internet, today, does not means only not having a library card, but being excluded from entering the big square. It means not being able to pronounce the word " $\mathrm{I}$ " nor the word "us". That is to say: in our ages any instance of recognition depends on a conscious use of social networks. The identification between internet and social media is

4 Time Person Of The Year 2017: The Silence Breaker, available at http://time.com/timeperson-of-the-year-2017-silence-breakers [Accessed 1.4.2020]; https://metoomvmt.org [Accessed 1.4.2020]. 
almost complete. Social networks spread news, influence politics - the case of the last American election seems very evident to $\mathrm{me}^{5}$ - help citizens to look for a work and represent themselves a source of employment and income - especially for young people. All of this require a deep reflection on digital divide(s). We need to discover why a part of the population is left out and behind and what consequence does it imply for the fruition of fundamental rights.

\section{THE DIGITAL DIVIDE(S)}

According to Carrie Bickner, the expression "Digital Divide" ("Digital Kluft", "Digital Fractura", "Fossé numérique", "Divario Digitale") ${ }^{6}$ was coined in America about forty years ago, within the researches dedicated to the relationship between ethnic groups and information technology. It became common in the late twentieth century, after Bill Gates and Al Gore, in Knoxville, Tennessee, used it with a different and broader meaning. Referring to the disparity in accessing ICT, Al Gore said that the intent of the Government would be the following: “... that our children will never be separated by a digital divide".

Nowadays, the term "digital divide" commonly refers to the difference between rich - people or countries - and poor ones in acceding information technologies. That is, the difference in the distribution of the technologies which currently govern the planetary processes of creation, distribution and

5 Russia-backed Facebook posts 'reached 126m Americans' during US election, avaible at https://www.theguardian.com/technology/2017/oct/30/facebook-russia-fake-accounts126-million, [Accessed 20.3.2020]

${ }^{6}$ IATE, InterActive Terminology for Europe, iate.europa.eu [Accessed 10.12.2017] 
retention of data, information and knowledge. A similar gap does not only concern the shameful inequality that separates rich and poor from the point of view of the production and sales of personal computers and other comparable instruments - such as smartphones, smartwatches and tablets nor the difference that separates people and countries in accessing the world wide web. From a cultural point of view, it indicates the uneven diffusion of the skills needed to obtain a benefit from the use of digital tools avoiding the many traps of the web: from viruses to phishing, to the most common malware or adware ${ }^{7}$. The term digital divide also refers to the difference between males and females, disabled and "normal" ones, young and old, workers and unemployed. For this reason, over the last twenty years we have moved from the discovery of the digital divide to the most complete and complicated analysis of the digital divides ${ }^{8}$.

Regarding its genesis and its development, the phenomenon seem connected to one of the most dangerous trends of the current economic system: the attitude of pushing towards the abyss those who already stand on the margins of society, rewarding with ever greater generosity those who already have money, power and success.

This hateful inequality, the exploitation of oceanic masses of weak subjects by a wealthy oligarchy, does not certainly represent an exclusive feature of

\section{AMATO MANGIAMELI, SARACENI 2018, 1-24;64-65;68-69.}

${ }^{8}$ To go beyond the simple binary distinction between who owns and who does not own certain objects or services - the so-called "have and have nots" - it is appropriate to take into consideration 1) the quality of the technical means available; 2) digital competence; 3) the support of social networks, or the possibility of being able to ask for help and information about the use of new technologies; 4) autonomy of use, i.e. the place of access and the possibility of use the Internet for one's own personal interest; 5) the range of activities that are undertaken on the Net (SARTORI 2006, 40). On the same topic, M. RAGNEDDA \& G. W. MUSCHERT (edit) 2018; RAGNEDDA \& G. MUSCHERT (edit) 2013; MOYO 2009; NORRIS 2001; DiMAGGIO and COHEN 2003; HARGITTAI and WALEJKO 2008, 239-256. 
our age. Yet, in the age we are living, the arrogance of the capitalist system seem to have reached its culmination - so that some authors believe it is coming to an imminent end. As we will consider later, the Internet could be considered as a tool at the service of financial liberalism, and, at the same time, the mean by which this same system will be definitively defeated and overcome. Before we deepen this topic, it's important to consider which are the characters of the digital divide in Europe and in Italy.

\subsection{IN EUROPE...}

DESI is a composite index that summarizes indicators of Europe's digital performance in order to track the evolution of EU member States in digital competitiveness. More exactly, it concerns six scores: 1) Connectivity; 2) Human Capital/Digital Skills; 3) Use of Internet by citizens; 4) Integrations of Digital Technology by Businesses; 5) Digital Public Services; 6) Research and Development ICT ${ }^{9}$.

The first score - Connectivity - measures the deployment of broadband infrastructure and its quality. As a matter of fact, the access to fast broadband-enabled services represent a fundamental condition for competitiveness. The second score - Human Capital/Digital Skills regards the skills needed to use ICT, that is to say, the know-how which consent taking advantage of the possibilities offered by a digital society. The skills range goes from "basic user" - that enable individuals to interact online and consume digital goods and services - to "advanced" ones, that empower the workforce to take advantage of technology for enhanced productivity

${ }^{9}$ https://ec.europa.eu/digital-single-market/en/desi [Accessed 8.3.2020]. 
and economic growth. It has to been mentioned that in $201743 \%$ of Europeans still do not have basic digital skills and 17\% had none; on the other hand, in 2018, 71\% of internet users employed in the UE use computer at work (with large disparities across countries). The third score measures the variety of activities performed by citizens who already are online. Such activities range from the simple consumption of content (videos, music, games, etc.) to the modern communication activities, such as online shopping and banking. It has to been said that the percentage of internet users engaged in heterogeneous online activities - such as reading news online $(70 \%)$; perform video or audio calls $(39 \%)$; using social networks $(63 \%)$; shopping $(66 \%)$ or using banking $(59 \%)$ - has increased slightly over the last couple of years. At least, in 2018, the share of people not using the internet fell in nearly all Member States.

The forth score - the Integration of Digital Technology - measures the digitization of businesses and their exploitation of the online sales channel. It has been proved that digital technologies can improve businesses. As we all know, ICT can enhance efficiency, reduce costs and better engage customers - collaborators or business partners. European digital activities are growing even in this field - for example: the use of a business software for electronic information sharing (from 26\% in 2013 to $36 \%$ of enterprises in 2015), sending electronic invoices (from 11\% in 2014 to $18 \%$ of enterprises in 2016) or using social media to engage with customers and partners (from 14\% in 2013 to $20 \%$ of enterprises in 2016 to $47 \%$ in 2017). Furthermore, in 2018 more than 12\% of enterprise analyse big data and $26,2 \%$ of enterprise invest in cloud services.

Moreover, Digital Public Services dimension measures the digitization of public services, focusing on eGovernment and eDemocracy: modernization and digitization of public services can lead to efficiency gains for the public administration as well as to the delivery of better services for the citizen. During the last five years we can notice an increase in the number of public services available online in Europe. At the same time, the score measuring the reuse of user data already known to the public administration as a way 
of facilitating the delivery of online services remained stable. According to DESI the most advanced digital economies in Europe belong on the northern States (such as Denmark, Finland, Sweden and Netherlands). On the other hand, regarding digital public service, Finland has the highest score, followed by Estonia the Netherlands and Spain ${ }^{10}$.

Last but not least, Research and Development of ICT regards the trends of ICT sector and R\&D provided by the European Commission. It has to be mentioned that EU's five biggest public funders of ICT and R\&D, in 2017, were Germany, The United Kingdom, France, Italy and Spain, while Cyprus had the highest of ICT GBARD ${ }^{11}$ as a share of total GBARD in 2017.

\section{2 ...AND IN ITALY}

According to Europe's Digital Progress Report (EDPR) ${ }^{12}$ in 2017 Italy ranks 25 ht out of $28 \mathrm{EU}$ Member States. Yet, it progressed a little faster than the EU average.

As a matter of fact, during the las years, the Italian Government has implemented a series of heterogeneous measures contained in the Italian Digital Agenda ${ }^{13}$. The Agenda can be defined as the set of actions and norms

${ }^{10}$ KATSIKAS, ZORKADIS (ed.), 2018; E. DI MARIA, S. MICELI (ed.), 2014; Open Government: Opportunities And Challenges For Public Governance, M. GASCó-HERNáNDEZ 2009.

${ }^{11}$ Government Budget Allocations for RひD.

12 https://ec.europa.eu/digital-single-market/en/news/europes-digital-progress-report$\underline{2017}$ [Accessed 22.3.2020].

${ }^{13}$ The Agency for Digital Italy (AgID) has the task of guaranteeing the achievement of the objectives of the Italian Digital Agenda in line with the European Digital Agenda. As part 


\section{Guido Saraceni IDIGITAL DIVIDE AND FUNDAMENTAL RIGHTS I ISSN 2675-1038}

put in place by the Italian Government for the development of technologies, innovation and the digital economy. This is one of the seven flagship initiatives of the Europe 2020 strategy, which sets the goals for growth in the European Union to be achieved by 2020 . According to it, Italy has developed its own national strategy, identifying priorities and methods of intervention, as well as actions to be carried out and measured on the basis of specific indicators, in line with the scoreboard of the European Digital Agenda.

In 2016, the Government adopted an aid scheme - endorsed by the European Commission in June 2016- aiming at promoting the deployment of passive access infrastructure enabling the development of NGA broadband networks in white areas. The effective implementation of the Ultra-broadband National Plan is essential in order to facilitate the progress with NGA coverage. Regarding to this topic, it is important to mention the Net4all public private partnership for ultra-fast broadband for industrial areas ruled by the region Emilia-Romagna, the project was one of the winners of the European Commission's European Broadband Awards in 2016.

Still there is much left to do. In our country, fast data transmission systems offer an high quality of services, yet, they do not reach the whole population, leaving many areas of the country without access to the fastest lane of the digital highway. More precisely, the Italian territory can be divided into two

of the 2014-2020 Partnership Agreement, the Council Presidency together with the Ministry of Economic Development, the Agency for Digital Italy and the Agency for Cohesion has prepared the national plans "National Ultra Broadband Plan" and "Digital Growth" for the pursuit of the objectives of the Digital Agenda. The Digital Agenda It was established on 1 March 2012 following the signature by all Member States of the European Digital Agenda presented by the European Commission in 2010. http://www.agid.gov.it/agenda-digitale/agenda-digitale-italiana [Accessed 10.02.2020]. 
different regions, partially or totally overlapping 1) areas covered by ADSL or optical fiber services ${ }^{14}$. Where citizens can use a relatively stable connection at affordable prices; 2) locations where the aforementioned services are not present or are limited in coverage and / or connection speed. In this last case a wide range of alternative technologies are normally available, such as the $56 \mathrm{kbit} / \mathrm{s}$ dial-up connection, the one or two-way satellite connection or the cellular data network.

However, these are alternatives that fail to offer a connection speed and a quality of services equivalent to that of normal ADSL. The old dial-up connection allows a download/upload too slow to be just compared to the ADSL service, moreover, it is easily exposed to the attacks of the pirates which, through the spread of malware, are able to disconnect a computer from its habitual server and connect it to a high-rate server. On the other hand, a satellite connection requires the installation of a satellite dish, it suffers from rather high latencies and it is, on the whole, more expensive than a wired one. Finally, the cellular data connection is rapidly evolving, but the service is not "stable" and overall does not offer a range of performance comparable to the ones of the broadband.

${ }^{14}$ ADSL connection works this way: a signal spread from a central station is not necessarily able to cover all the municipality that has been assigned to its station, or even to reach the nearest signal station. The data transmission speed decreases linearly as the distance from the central unit increases. As the distance is doubled, the connection speed is halved. Moreover, the signal tends to die or lose quality also due to the interference of nearby cables - the so-called "near-end cross talk". Given that usually a municipality can count only one power station, it would be necessary for the entire population to live within a radius of $7 \mathrm{~km}$ from the only source of signal to be fully reached by the fast ADSL. 


\section{THE ANCIENT DUTY OF FEEDING THE HUNGRY IN THE EUROPEAN CULTURE}

Poverty is a topic of the highest level and deserves the utmost respect and attention. As if it were a philosophical matryoshka, it carries within an incredible list of provocative and delicate problems. Just to mention some, without any pretense of completeness or hierarchical organization: charity, marginalization, weakness, acceptance... and therefore, equality, solidarity, social justice, loneliness. That is why reflecting on this topic can help us in gaining an elective perspective by which consider the era we are living in, analyze its weaknesses and focus its main distortions. As if it represents a litmus test for post-modernity ${ }^{15}$.

As a first approximation, there are two different ways of considering poverty. The first is crude and strictly materialistic. Following this first line of interpretation, poor are those who have neither food nor drink. If poverty were reduced to this - as often happens - it would represent a mere economic problem. According to a different - and in my opinion more correct - line of thought, poverty has an eminently existential nuance. This second speculative perspective does not, and in any way, deny the relevance of material goods, but suggests that, alongside the lack of sustenance, there are equally serious forms of weakness which make a human being dramatically "poor" and therefore in need of being welcomed and helped.

15 With the usual acumen, Jesús Ballesteros writes that for a very long historical period, which goes from the industrial revolution up to today, the most hateful form of violence has been represented by the "radically unjust distribution of wealth". Returning to a wellknown weberian thesis, the author points out that the absence of any moral remorse in the accumulation of wealth - and in the consequent exploitation of the poor - is closely connected with the spread of the Calvinist principle for which success is a proof of divine predilection (BALLESTEROS 2005, 20 ss.). 
This second line of thought appears to be very relevant fort the European tradition. Because the duty of helping the poor is one of its deepest root. It is no coincidence that for the Greeks, the Jews and the Christians, divinity frequently assumed the appearance of the poor and descended on the earth as a disguised traveler, in order to control the reactions of human beings and eventually punish them for their selfishness ${ }^{16}$. As a matter of fact, Greek mythology, Jewish traditional Christian religion ${ }^{17}$ have always merged the condition of the poor with the one of the outcast, the sick and the stranger ${ }^{18}$.

Paradoxically, in the Gospels we find two different descriptions of poverty as a bliss. Let's start from the reconstruction of Luke: he places the

${ }^{16}$ In this regard, the story of Filemone and Bauci, that Ovid tells in The Metamorphoses, is quiet significant: Zeus and Hermes enter a village of Phrygia Minor, pretending to be beggars. Nobody welcome or help them, except for two humble and old peasants who open their house and share a frugal dinner. At a certain point of the dinner, both deities, drunk with wine, decide to reveal their true identity and destroy the whole village for its cruelty - not without having granted a reward to the only charitable and hospitable people who met on their journey. For a discussion of the mentioned myths, SARACENI 2012, 136.

17 Yet the Christian tradition insist on the sacredness of the poor, thus identifying the face of Christ in the face of the poor, the thesis that Christ was present in the poor, in general (an idea reaffirmed by many preachers of the fourth and fifth centuries), was based on the hypothesis that, among the anonymous crowd of the usual beggars, it was possible to stumble at least in a beggar whose remains were hidden by Christ himself (BROWN 2014, 707).

18 In the Odyssey we often read that supplicants and beggars must be respected and welcomed, because it is Zeus who sends them. The Jewish religion reaffirms this same concept, narrating the destruction of Sodom and Gomorrah: a traveler arrives late at night in the city, but is persecuted by the sons of Belial, who want to abuse him. So, he finds refuge in the home of a just man, who, in order not to deliver the stranger to his tragic destiny, offers to the sons of Belial his daughters. After receiving a refusal, the just man calms the fury of his unjust citizens by offering them his concubine. As a direct consequence, this wounded family will be the only one saved from the divine punishment. 
discourse on the beatitudes in a flat place - normally identified with Galilee. According to him, the Lord does not spoke, in general, about those who will be happy in the future, but addressed himself directly to the crowd "Blessed are you, poor" 19 . Furthermore, he spoke for the present, giving to understand that the condition in which the poor are is, already now, a condition of bliss - "yours is the kingdom of God". On the other hand, Matthew places this discourse on a mountain - identified by many as a hill overlooking Lake Tiberias. Even Matthew refers of an happiness that does not necessarily have to be projected into a utopian future, but it's already and completely present - "of them is the kingdom of heaven". Yet, unlike Luke, he quotes the phrase in an impersonal form - "blessed are the poor" - not "blessed are you, poor" 20 . Above all, Matthew uses the very important expression "of spirit" in order to specify the meaning of the word "poor"

We can thus underline some essential indications for our understanding of the digital divide in the European culture. The first is that, according to the testamentary tradition, poverty must not be feared, because the poor is holy. Yet, he is not sacred for the mere fact of being indigent, as an iconic metaphor of the humble, the charitable, the poor in spirit. The second, even more important, is that for the Christian religion - for the Jewish tradition and for the Greek philosophy - the poor must always be helped and accepted as the weakest one. It means that in the European cultural tradition, poverty is an existential condition which involves the sick, the

${ }^{19}$ RAVASI 2012, 32.

${ }^{20}$ Besides, - he does not mention "God", but in a more coherent way with Jewish language and culture he prefers to use the expression "Kingdom of Heaven".

${ }^{21}$ This is not just a difference. In the first case we face a present condition, objective and material - as objective and material are poverty, sickness, loneliness. In the second, poverty it's a spiritual condition towards which everyone must strive in order to be blessed. The poor is sacred because of his humility. He is forced by the call of the stomach to bend towards another human being. Begging for help. On the contrary, the rich can easily give in to the temptation to lock himself in his golden tower. Poverty is therefore a way to access charity. 
widow, the rejected and the foreigner as they all are excluded subjects who need to be rescued and saved from their misery.

\section{CONCLUSIONS}

It has been said that "the difference between those who have internet and those who do not adds another crucial split to the sources of inequality and social exclusion - in a complex interaction that seems to increase the gap between the promises of the information age and its hopeless reality for many people in the world" ${ }^{22}$. In support of this thesis, Manuel Castells proposes eight core topics: 1) the logic of networking and new economy favors an extreme irregularity in the growth of economic and social development 2) Education, information, science and technology are critical points in the creation of value 3) The global economy is structurally exposed to the vortexes of financial flows that cause sudden periods of crisis, which, in turn, push the weakest towards the margins of society, allowing richer to increase their heritage 4) New information technologies devalue the land, eliminating traditional agriculture - are therefore leading to a rural exodus of colossal dimensions 5) National governments have gradually lost power due to global capital flows and information that, in turn, rule all supranational institutions 6) The global criminal economy exploits new technologies to assert and destabilize society 7) Governments suffer from a widespread crisis of legitimacy 8) The phenomena listed above can lead to civil wars and large-scale banditry. In all these cases, the birth of the online society, which Castells himself celebrated in a book soon became a classic, seems to represent a negativity, an element that collaborates, together with

${ }^{22}$ CASTELLS 2001, 231 and ss. 
others and equally deleterious phenomena, to the selfish fragmentation of society, favoring its disintegration.

The thesis according to which the diffusion of the Internet, together with the digital divide that it implies and supposes, would amplify existing inequalities - in a society already strongly polarized like the one we are living in - its normally identified as the thesis of the stratification. Based on the so-called "St. Matthew effect"'3, it assumes that only some citizens, who have an already higher cultural and economic condition, would be able to further improve, capitalize and exploit opportunities offered by networks. The spread on the ICT would end up increasing the distance that separates the most advantaged from the weakest sections of the population.

On the other hand, Jeremy Rifkin argues that both capitalism and socialism are destined to sink into a society based on the collaborative paradigm spread by the Internet - and in particular by the advent of the commons which the philosophy of the network implies and supposes ${ }^{24}$. In support of this thesis, it would be possible to cite many important studies that sociologists, philosophers and informatics have dedicated to the act of sharing as a structural paradigm for the network. In particular, the peer to peer protocol, the open source software and end-to-end architecture would

${ }^{23}$ The expression refers to the words used by Matthew 13.12 and 25.29 - "For whoever has, to him more will be given, and he will have abundance; but whoever does not have, even what he has will be taken away from him". This is the virtuous circle that interests and privileges those who already occupy high positions in the social structure, thus favoring a widening of the disparities. SARTORI 2006, 43-44; BARABÀSI 2004, 89-102.

${ }^{24}$ While market capitalism is based on personal interest and is dominated by material gain, social commons is animated by collaborative interests and a deep desire to connect with one another and, indeed, to share. What gives today more importance to Commons than at any other time in its history is that now we are building a high-tech global technology platform, whose essential characteristics are potentially able to optimize the values and operating principles that animate this ancient institution (RIFKIN 2015, 28). 
seem to represent excellent alternatives to the competitive egoism typical of capitalism $^{25}$.

Moreover, Rifkin thinks that is not at all said that the spread of the Internet will necessarily amplify differences and social inequalities: with the passing of the years even the slowest groups in adopting the Internet, for scarce economic, cultural or social resources, will have the opportunity to recover the lost ground. In turn, this kind of leveling will produce others - working as an extraordinary factor of democracy and equality. As a matter of fact, network users have the opportunity to share many important cultural resources - such as movies, books and songs. Not only that, they can exploit the potential of shared computing to create a gigantic machine with variable morphology. In other words, peer to peer technology can be used to create a mega computer which could solve, in a completely and structurally free of copyright way, problems so complicated that could never be set by a single research group - by a single company or a single State ${ }^{26}$.

Furthermore, the increasingly widespread dissemination of open source programs implies that software - one of the main evolutionary resources of all times - can be distributed on the web within its source code "open" that is to say: without any impediment or block, so that anyone have the

25 Chris Carlsson writes that the Internet reveals an unlimited abundance that stimulates sharing and cooperation to its advantage, and digital common goods that strengthen interconnection and human interdependence. In late capitalism, a world of oppressive barbarism and alienating isolation, the powerful appeal of communication inspires a passionate commitment and considerable investment of time for millions of people. Participatory common goods feed all human relationships, from the banal buying and selling to the unbridled sharing of poetry, art and music. In the expanding autonomous communicative spaces a post-capitalist life based on generalized abundance is prefigured (C. CARLSSON 2009, 104).

${ }^{26}$ RIFKIN 2015. 
opportunity to study its algorithm, understand how it works, change it and eventually spread a new version. Considering that in ninety-nine percent of the cases the open source software is shared in the network under a General Public License, and considering, above all, that it normally works better than the so-called "proprietary" software, we can understand how the genesis and the development of the network society can help in fighting the worst distortions of world capitalism, helping the free sharing of knowledge in place of the old, egoistic and competitive, paradigm ${ }^{27}$. Internet, within the ethics it implies and spread, can help society in finding a new paradigm. Alternative to the protestant ethics which Max Weber has been so well discussing in his masterpiece ${ }^{28}$.

Finally, the Internet allows the active participation of citizens in the management of public affairs, makes it possible to control political power, unmask its lies and criticize its actions. The structure of the old means of communication for the masses implied that they were entirely entrusted to the care of a cultural mediator. It means that the responsibility for the content was placed, in whole or in part, on the shoulders of an editorial (board) or network editor. This mechanism therefore implied a preventive

${ }^{27}$ A good example is the Seti project, Seti (Search for Extraterrestrial Intelligence) analyzes the radio waves trying to prove the existence of intelligent life in space, by recording the noise of the radio spectrum we receive on our planet, which is then analyzed by a computer who are looking for revealing signs of something not explained [...] soon realized that renting computers that analyze the recording of these radio waves would have resulted in increasingly prohibitive costs. Therefore, researchers at the University of Berkeley had an idea : facilitate the distribution of portions of these recorded data to machines on the Net and then allow these machines to perform the necessary computation (LESSIG 2006,139). ${ }_{28}$ The radicality of hacking consists in the proposal of an alternative spirit to the network society - a spirit that finally puts into question the Protestant dominating ethics, and this is the only time when hackers really become crackers: because they are trying to forcing the lock of the iron cage. As a matter of fact, Protestant ethics will not suddenly be replaced by something else, it will take time: it is so deeply rooted in our today's consciousness that it is often seen simply as "human nature" (HIMANEM 2001, 79). 
control on information and ideas, a censorship which intervened at the source, in order to decide which content should - or should not - be published.

On the one hand, all this deposed in favor of the truthfulness and seriousness of the information: an important publisher - a national newspaper or network - would not probably publish inaccurate, misleading or even false news, invented of sound plant. On the other hand, this mechanism drastically limited the democratic nature of information, favoring its control by political power. It is no coincidence that the most important politicians of the most civilized Western democracies are often closely linked to the publishing world - when they do not even cover the role of publishers.

All the mentioned seems to me very important for the enjoyment of fundamental rights. A brief introduction on the topic may help, before we deepen the issue. From a theoretical point of view, there are many, important, and known problems with fundamental rights ${ }^{29}$. 1) Since 1948, the number of fundamental rights has been constantly growing. It is almost impossible to establish how many rights are, nowadays, "fundamental". As a matter of fact, this growth clashes with the same definition of "fundamental" rights, which seems to refer to a few bunch of basic rules that cannot be broken nor negotiated. On the one hand, the proliferation of rights could be thought as a proof of the spiritual and juridical improvement of the human kind. 2) On the other hand, it may seem that we are very good in declaring new rights, but not able to improve their effectiveness. 3) What happens if a State does not respect one of these rights? Do they oblige only the members of a certain community - such as the European one - or they are truly "universal rights" which oblige each and every Government? 4) Last but not least, it is not simple to decide what

${ }^{29}$ COTTA 2004, 9-35; BALLESTEROS 1984, 110-118; D’AGOSTINO 2000, 241-252; AMATO MANGIAMELI 2004, especially, 65-105. 
to do when one or more of these rights clashes one with another - eg. the right to work vs the right to health, the right of being informed vs privacy, the right to be forgotten vs. free speech. Potential clashes keep growing, as the list of new rights $\mathrm{do}^{30}$.

All of the mentioned affects also the fundamental rights declared in the European Charter. The chart is obviously European - not Universal. As a consequence, an European State which does not respect the fundamental rights that it claims could be punished by the Community - trough a specific juridical process studied to give them a concrete effectiveness. Still, we should answer all the other mentioned question: in which way can we consider these rights to be "fundamental"? Are they more fundamental then the ones declared in 1948? Which right should win and survive, in case, of clash? Does a "more fundamental" right exists? The latter is probably the most important question and the more difficult to answer.

Giving an answer to the mentioned questions is not the specific task of this paper. Assuming that "fundamental rights" do exist. Assuming that they are every day more important - under a juridical, sociological and political point of view -, it seems to me that the digital divide(s) can be thought as the most important problem that we have to face if we want to guarantee their fruition. The inequality in accessing digital technologies - the lack of resources, connections and information - has a dramatic impact on the lives of citizens, preventing them - today more than ever - from enjoying their fundamental rights - such as, for example, the right to health, the right to be informed or the right to work - and to participate actively in the democratic life of their own country ${ }^{31}$. Being excluded from the internet

${ }^{30}$ For a deep analysis of the sentences of the European Court of Justice - with a specific regard to its prerogatives and limits, MANGIAMELI 2007, 2017.

31 The Internet allow people with reduced mobility to participate actively in the social life, not only do smartphones help people with speech problems communicating in many ways that were not even remotely imaginable a few years ago, but new information technologies 


\section{Guido Saraceni IDIGITAL DIVIDE AND FUNDAMENTAL RIGHTS I ISSN 2675-1038}

means living on the borders of society. Without any doubt, it can be considered as the worst and more dangerous form of poverty, exclusion and margination

\section{REFERENCES}

AA. VV., E-Democracy - Privacy-Preserving, Secure, Intelligent E-Government Services: 7th International Conference, E-Democracy 2017, Athens, Greece, December 14-15 2017, KATSIKAS, Socratis K. and. ZORKADIS, Vasilios (ed.), New York 2018;

AA. VV., Theorizing Digital Divides, RAGNEDDA, Massimo \& MUSCHERT, Glenn W., (edit), New York 2018; The Digital Divide: The Internet and Social Inequality in International Perspective, M. Ragnedda \& G. W. Muschert (edit), New York 2013;

AA. VV., On Line Citizenship: Emerging Technologies For European Cities, DI MARIA, Eleonora., MICELI, Stefano (ed.), New York, 2014.

AMATO MANGIAMELI, Agata C., Stati post-moderni e diritto dei popoli, Torino, 2004.

AMATO MANGIAMELI, Agata C., Informatica Giuridica, Torino 2005;

AMATO MANGIAMELI, Agata; SARACENI, Guido, I reati informatici, Torino, 2018.

allow disabled getting in contact, forming communities of mutual help and creating a critical mass. All this could help them in spreading awareness about their difficulties politically influence the choices of the community to which they belong (JAEGER 2012). This is just an example of what new information technologies can do in helping the less lucky and more marginalized citizens in improving their social condition. 
BALLESTEROS, Jesús, Repensar la paz, Madrid, 2005.

BALLESTEROS, Jesús, Sobre el Sentido del Derecho, Madrid, 1984.

BARABÁSI, Albert László, Link. La nuova scienza delle reti, Torino, 2004.

BERNERS LEE, Tim, L'architettura del nuovo web. Dall'inventore della rete il progetto di una comunicazione democratica, interattiva e intercreativa, Milano, 2001.

BERNERS LEE, Tim, Weawing the web: the original design and the ultimate destiny of the world wide web, New York, 2007.

BROWN, Peter, Per la cruna di un ago: la ricchezza, la caduta di Roma e lo sviluppo del cristianesimo, 350-550 d.C., Torino, 2014.

CARLSSON, Chris, Now Utopia, come il ciclismo creativo, l'orticoltura comunitaria, la permacoltura, la galassia P2P e l'ecohacking stanno reinventando il nostro futuro, Milano, 2009.

CASTELLS, Manuel, Galassia Internet, Milano, 2001.

CASTELLS, Manuel, La nascita della società in rete, Milano, 2002.

COTTA, Sergio, Attualità e ambiguità dei diritti fondamentali, in Id. Il diritto come sistema di valori, Milano, 2004.

D’AgOSTINO, Francesco, Lezioni di filosofia del diritto, Torino, 2000.

GASCÓ-HERNÁNDEZ, Mila, Open Government: Opportunities And Challenges For Public Governance, New York, 2009.

HARGITTAI, Estzer and WALEJKO, Gina, "The participation divide: content creation and sharing in the digital age 1", Information, Communication \&o Society, $\mathrm{n}^{\circ} 11,2008$..

HIMANEN, Pekka, Etica Hacker, Milano, 2001. 
JAEGER, Paul T., Disability and the Internet: Confronting A Digital Divide, London, 2012.

JOHNSON, Steven, La nuova scienza dei sistemi emergenti: dalle colonie di insetti al cervello umani, dalle città ai videogame e all'economia, dai movimenti di protesta ai network, Milano, 2004.

LESSIG, Lawrence, Il futuro delle idee, Milano, 2006.

LÉVY, Pierre, Collecting Intelligence: mankind emerging world in cyberspace, New York, 1999.

MANGIAMELI, Stelio, Il contributo dell'esperienza costituzionale italiana alla dommatica europea della tutela dei diritti fondamentali, http://www.giurcost.org/studi/mangiameli.html, 2017.

MANGIAMELI, Stelio, La tutela dei diritti fondamentali nell'ordinamento europeo, in Itinerari giuridici. Per il quarantennale della Facoltà di Giurisprudenża dell'Abruzzo, Milano, 2007.

MANGIAMELI, Stelio, "State, European integration, and globalization. New challenges for constitutionalism." Humanities and Rights Global Network Journal, n¹, 2019. DOI: https://doi.org/10.24861/2675-1038.v1i1.17

MOYO, Last, "The digital divide: scarcity, inequality and conflict", Digital cultures: understanding new media, CREEBER, Glenn and ROYSTON, Martyn (ed), London, 2009.

NORRIS, Pippa, Digital divide: civic engagement, information poverty, and the Internet worldwide, Cambridge, 2001.

DI MAGGIO, Paul and COHEN, Joseph, Information inequality and network externalities: a comparative study of the diffusion of television and the Internet, Working Paper 31, Princeton, 2003. 


\section{Guido Saraceni IDIGITAL DIVIDE AND FUNDAMENTAL RIGHTS I ISSN 2675-1038}

RAVASI, Gianfranco, "Makárioi hoi ptochoi": blessed you poorr, in G. Ravasi, $A$. Sofri, Beati i poveri in spirito perché di essi è il regno dei cieli, Torino 2012, 32.

RHEINGOLD, Howard, Smart Mobs: the next social revolution, New York, 2003.

RIFKIN, Jeremy, La società a costo marginale zero: l'internet delle cose, l'ascesa del «Commons» collaborativo e l'eclissi del capitalismo, Milano 2015.

SARACENI, Guido, Luoghi della giustizia, Napoli, 2008.

SARACENI, Guido, Ospitalità: un valore giuridico fondamentale, Milano, 2012.

SARTORI, Laura, Il divario digitale. Internet e le nuove disuguaglianze sociali, Bologna 2006.

SITOGRAPHY

http:/ / www.agid.gov.it/agenda-digitale/agenda-digitale-italiana [Accessed 10.2.2020]

https: / / ec.europa.eu/digital-single-market/en/desi

[Accessed 8.3.2020].

https://ec.europa.eu/digital-single-market/en/news/europesdigital-progress-report-2017 [Accessed 22.3.2020].

IATE, InterActive Terminology for Europe, iate.europa.eu [Accessed 10.12.2017]

https://metoomvmt.org [Accessed 1.4.2020].

Russia-backed Facebook posts 'reached 126m Americans' during US election, avaible 
https://www.theguardian.com/technology/2017/oct/30/facebookrussia-fake-accounts-126-million, [Accessed 20.3.2020].

Time Person Of The Year 2017: The Silence Breaker, avaible at http://time.com/time-person-of-the-year-2017-silence-breakers [Accessed 4.4.2020]; https://metoomvmt.org [Accessed 1.4.2020]. 